\title{
Metacontrast masking as a function of mask energy
}

\author{
BRUNO G. BREITMEYER \\ Neurologische Universitätsklinik, Freiburg, West Germany
}

\begin{abstract}
Two metacontrast experiments investigated the effects of the relation between the energy of a black target disk and the energy of a black annular mask. The resulting masking functions indicate that at short stimulus onset asynchronies (SOAs), target contrast suppression requires higher mask energies than are required at intermediate SOAs. The relevance of these findings to current sustained-transient channel models of metacontrast is discussed.
\end{abstract}

The type of metacontrast function one obtains when a visual target is followed at variable stimulus onset asynchronies (SOAs) by a spatially adjacent mask is, among other things, a function of the energy ratio between the target and the mask. For instance, Weisstein (1972) has shown that one can obtain a transition from nonmonotonic U-shaped metacontrast functions to monotonic functions by increasing the energy of the mask relative to that of the target. The range of targetto-mask energy ratios used by Weisstein varied from 1.0 to .0625 . At a ratio of 1.0 (target and mask of equal energy), a U-shaped function was obtained, that is, masking was weak at low and high SOAs and strongest at intermediate SOAs. At a ratio of .0625 (target substantially weaker than mask), a monotonic function was obtained, that is, masking was strongest at short SOAs and decreased as SOA increased.

The present experiment investigated the effects of varying mask energy relative to target energy in the context of recent sustained-transient channels models of metacontrast (Breitmeyer \& Ganz, 1976; Matin, 1975; Weisstein, Ozog, \& Szoc, 1975). Breitmeyer and Ganz (1976), for instance, suggest the existence of two types of target-mask inhibitory interactions in a metacontrast situation. One interaction, dominating at short SOAs, is the inhibition of target-sustained activity by masksustained activity. The other interaction, dominating at intermediate SOAs, is the inhibition of target-sustained activity by mask-transient activity. Since, as noted above, increasing the energy of the mask relative to that of the target produces substantial increases in otherwise

This research was done while the author was on leave of absence from the Department of Psychology, University of Houston, from July 1976 to July 1977, during which time he was a fellow of the Alexander von Humboldt Foundation, Bonn-Bad Godesborg, West Germany. He thanks the Foundation for its generous support. Thanks also go to Lothar Spillman, who provided excellent research facilities. This research was supported by Deutsche Forschung Gemeinschaft SFB 70, Teilprojekt A6. Reprint requests should be sent to the author at the following address: Department of Psychology, University of Houston, Houston, Texas 77004. small masking magnitudes at short SOAs, one may infer that the former sustained-on-sustained inhibition requires a higher mask energy to manifest itself, that is, to attain threshold, than does the latter transient-onsustained inhibition.

\section{METHOD}

\section{Subjects}

The subjects were the author and a 21-year-old male (R. K.) who was a student at a local gymnasium in Freiburg. Both subjects had normal vision and R. K., although an experienced psychophysical observer, was naive regarding the purpose of the experiment.

\section{Apparatus and Stimuli}

Stimuli were presented on white index cards at a viewing distance of $125 \mathrm{~cm}$ in a three-channel Scientific Prototype tachistoscope (Model GB). The target, presented in Channel 1, consisted of a black disk drawn with India ink on a white index card. The contrast of the disk against the surround was .9. The disk was centered 1.25 deg directly above fixation. The diameter of the disk was $.67 \mathrm{deg}$. The fixation field was presented in Channel 2. The mask, presented in Channel 3, consisted of a black annulus which optically surrounded the disk. The contrast of the annulus was .9; its inner and outer diameters were .67 and $1.10 \mathrm{deg}$, respectively. A serial array of 10 patches of varying reflectance was presented $1.5 \mathrm{deg}$ below the fixation cross in Channel 2. Each array was .30 by $.30 \mathrm{deg}$ and arranged in two rows of five, with reflectance of the patches increasing in roughly $.12 \log$ unit steps from $8.6 \%$ for the upper left patch to $98.2 \%$ for the lower right. The illumination of the tachistoscope was set so that the reflected luminance of the white index cards was $20 \mathrm{fL}\left(68.5 \mathrm{~cd} / \mathrm{m}^{2}\right)$.

\section{Procedure}

The subject initiated the stimulus sequence, which consisted of a 16-msec presentation of the disk, followed at intervals ranging in $20-\mathrm{msec}$ steps from 0 to $120 \mathrm{msec}$ by the fixation field, in turn followed by the annulus of variable duration, followed by the fixation field, which remained on until the initiation of the next trial about $15 \mathrm{sec}$ later. The SOAs between target disk and mask annulus thus could be one of the following: $16,36,56,76,96,116$, or $136 \mathrm{msec}$. After each trial the subject was to match the apparent contrast of the disk to one of the patches located below fixation in the fixation field present between trials. He was to assign a value of 1 to the apparent contrast if it matched most closely the darkest patch in the upper left of the patch array, a value of 10 if it matched the 


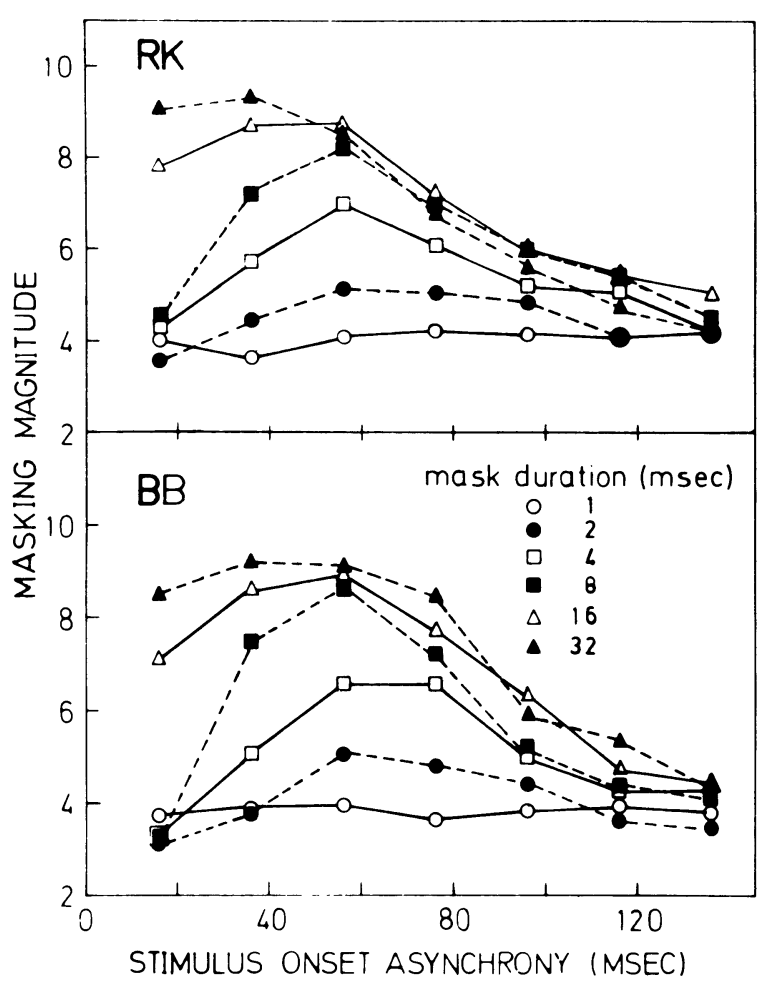

Figure 1. Masking magnitude as a function of stimulus onset asynchrony and mask durations as indicated.

brightest patch in the lower right of the patch array, and intermediate values if it matched most closely correspondingly intermediate gray patches. Since the target disk was black, a higher value attached to its apparent brightness corresponded to greater contrast reduction or masking. Thus, the brightness judgments ranging from 1 through 10 were converted directly to a measure of the metacontrast suppression effects.

Whereas the disk energy was fixed, the mask energy was varied by varying its duration. The mask durations were $1,2,4$, 8,16 , and $32 \mathrm{msec}$. In any given daily session, six blocks of trials with 28 trials/block were run, with one block devoted to each mask duration. Within a block four trials were devoted to each of the seven SOAs. The order of SOAs within a block and order of mask durations in a daily session were randomized. A session, including rest between blocks and warm-up and light adaptation prior to them, lasted approximately $2.5 \mathrm{~h}$. Over four sessions, 16 trials were run per SOA for every mask duration. For each SOA, the 16 disk-brightness judgments were averaged and served as an index of the magnitude of contrast masking.

\section{RESULTS AND DISCUSSION}

The results for both subjects are shown in Figure 1. Masking magnitude is plotted as a function of SOA, with mask duration as the parameter. Several features of the results are noteworthy. For both subjects, there was little or no masking at the mask duration of $1 \mathrm{msec}$; moreover, at the target SOA of $136 \mathrm{msec}$, none of the mask durations produced a noticeable mask effect. Presumably, at that large an SOA the target-mask inhibitory interactions are minimal or absent, at least over the range of mask durations used here.
Another noteworthy feature is that mask magnitude increased with mask duration. As mask duration increased, the U-shaped nature of the masking function initially became more pronounced and, at the longest mask durations, the masking function began to assume a more monotonic form. The latter effect is primarily due to an increase in the masking magnitude at short SOAs. At longer SOAs, the effect seems to be saturated for mask durations of $8 \mathrm{msec}$ or higher.

As a function of mask duration, the differences in masking effects at short and intermediate SOAs are made more strikingly apparent in Figure 2. Here mask magnitude is plotted as a function of mask duration (on a $\log$ millisecond scale) for the shortest SOA of $16 \mathrm{msec}$ and for the SOA of $56 \mathrm{msec}$, where the peak in the U-shaped masking functions occurred. The differences at these two SOAs are obvious. At the SOA of $56 \mathrm{msec}$, the effectiveness of the mask increased to a maximal value as duration increased from 1 to $8 \mathrm{msec}$ and then saturated at that value for higher durations. However, at the SOA of $16 \mathrm{msec}$, the mask effectiveness remained low and constant for durations ranging from 1 to $8 \mathrm{msec}$ and then began to increase rapidly at higher durations.

That is, at SOAs at which peak masking occurred in the U-shaped functions, the mask had lower threshold and saturation values compared to those obtained at the lowest SOA. This result would suggest, as argued above, that the sustained-on-sustained inhibition which

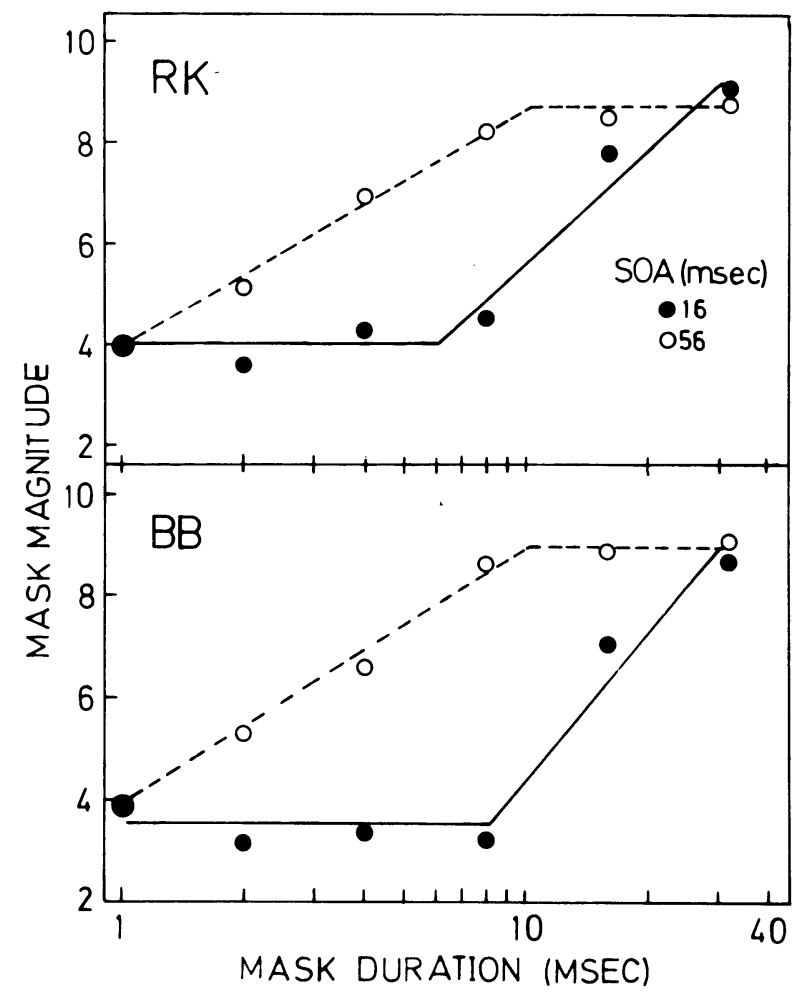

Figure 2. Masking magnitude as a function of mask duration at target-mask onset asynchronies of 16 and $56 \mathrm{msec}$. 
manifests itself at a short SOA of $16 \mathrm{msec}$ has a higher threshold and saturation level than the transient-onsustained inhibition which manifests itself at an intermediate SOA of $56 \mathrm{msec}$.

Such an interpretation is consistent with electrophysiological findings (Ikeda, Note 1) and psychophysical findings (Keck, Pallela, \& Pantle, 1976; Kulikowski \& Tolhurst, 1973; Tolhurst, 1973) which indicate that generally sustained channels indeed have a higher threshold and saturation level than do transient channels.

\section{REFERENCE NOTE}

1. Ikeda, H. Personal communication, August 1975.

\section{REFERENCES}

BREITMEYER, B. G., \& GANz, L. Implications of sustained and transient channels for theories of visual pattern masking, saccadic suppression, and information processing. Psychological Review, 1976, 83, 1-36.
Keck, M. J., Palella, T. D., \& Pantle, A. Motion aftereffect as a function of the contrast of sinusoidal gratings. Vision Research, 1976, 16, 187-191.

Kulikowski, J. T., \& Tolhurst, D. J. Psychophysical evidence for sustained and transient detectors in human vision. Journal of Physiology [London], 1973, 232, 149-162.

Matin, E. The two-treatment (masking) paradigm. Psychological Review, 1975, 82, 451-461.

TolnURST, D. J. Separate channels for the analysis of the shape and the movement of moving visual stimuli. Journal of Physiology [London], 1973, 231, 385-402.

Weisstein, N. Metacontrast. In D. Jameson \& L. M. Hurvich (Eds.), Handbook of sensory physiology (Vol. 7, Part 4: Visual psychophysics). Berlin: Springer-Verlag, 1972.

Weisstein, N., Ozog, G., \& Szoc, R. A comparison and elaboration of two models of metacontrast. Psychological Review, $1975,82,325-343$. 